\title{
ERRATUM
}

\section{English Language Training in the Workplace}

\section{Case Studies of Corporate Programs in China}

\section{Xie Qing}

(C) Springer International Publishing Switzerland 2016

$\mathrm{X}$. Qing, English Language Training in the Workplace, Technical and Vocational

Education and Training: Issues, Concerns and Prospects 22,

DOI 10.1007/978-3-319-30157-0

DOI 10.1007/978-3-319-30157-0_12

The Author name was incorrect in the Table of contents and Chapter opening pages of all the chapters. The name should read as Qing Xie.

The online version of the updated original book can be found at http://dx.doi.org/10.1007/978-3-319-30157-0 